GOMIDE, A.P.C. et al. Glicerina bruta na alimentação de aves e suínos. PUBVET, Londrina, V. 5, N. 26, Ed. 173, Art. 1167, 2011.

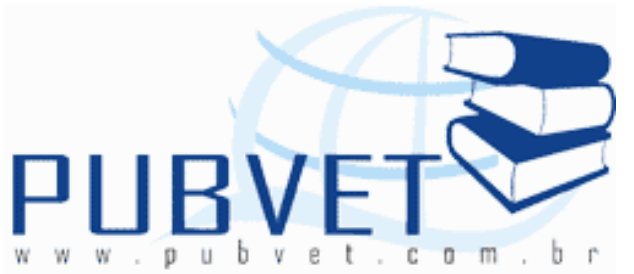

PUBVET, Publicações em Medicina Veterinária e Zootecnia.

\title{
Glicerina bruta na alimentação de aves e suínos
}

\author{
Ana Paula Cardoso Gomide ${ }^{1}$; Anderson Lazarini Lima2; Paulo César Brustolini3 ; \\ Aloizio Soares Ferreira ${ }^{3}$; Bruno Andreatta Scottá1; Larissa Rdrigues de \\ Azevedo Câmara ${ }^{1}$
}

\begin{abstract}
1 Mestranda (o) do Programa de Pós-Graduação em Zootecnia da Universidade Federal de Viçosa - UFV.

2Doutorando do Programa de Pós-Graduação em Zootecnia da Universidade Federal de Viçosa - UFV.

3Professor do Departamento de Zootecnia da Universidade Federal de Viçosa UFV.
\end{abstract}

\section{Resumo}

No atual contexto mundial, em que o milho está sendo usado para a produção de etanol, a utilização de alimentos alternativos para a alimentação animal assume papel relevante. A suinocultura e avicultura brasileira têm passado por constantes períodos de instabilidade, principalmente pelo baixo preço do produto associado aos custos elevados de produção e a alimentação tem sido o componente de maior participação no custo total de produção, representando um percentual de 70,0 a 75,0 \% dos custos totais da atividade. Devido a isso e em virtude dos ingredientes mais utilizados nas rações de suínos e aves no Brasil serem o milho e o farelo de soja, qualquer variação no preço destes insumos pode ter reflexos diretos na margem de lucro do produtor. Nos 
GOMIDE, A.P.C. et al. Glicerina bruta na alimentação de aves e suínos. PUBVET, Londrina, V. 5, N. 26, Ed. 173, Art. 1167, 2011.

últimos anos, esforços de pesquisas envolvendo a utilização de alimentos alternativos, com destaque para os subprodutos ou resíduos resultantes do processamento industrial de produtos agrícolas e de práticas modernas de mecanização, vêm despertando o interesse da comunidade científica. As pesquisas têm sido fundamentais para que se descubram novas formas de utilização dos produtos e subproduto e as limitações destes para as diferentes categorias animais dentro de cada espécie. Atualmente, além das pesquisas do ramo agropecuário, estudos sobre o emprego de fontes renováveis de energia têm sido intensificados. Entre as fontes renováveis tem recebido grande atenção o biodiesel. Porém, o aumento da produção de biodiesel só poderá ser economicamente viabilizado, se forem encontradas novas aplicações para os subprodutos gerados, como por exemplo, a glicerina bruta. Tem-se constatado que para cada $90 \mathrm{~m}^{3}$ de biodiesel produzido pela reação de transesterificação, são gerados $10 \mathrm{~m}^{3}$ de glicerina bruta. A glicerina quando purificada pode ser usada na produção de tabacos, na indústria alimentícia, em bebidas e para produção de cosméticos. No entanto, são necessários processos complexos e de alto custo para que essa matéria-prima alcance as exigências em grau de pureza necessárias para estes fins. Com o recente impulso na produção do biodiesel e a disponibilidade de grande quantidade de glicerina bruta, tem havido interesse no seu uso em rações para animais. Há estudos, cujos resultados indicam a possibilidade de uso deste subproduto em rações como fonte de energia para suínos e aves, pois ela é rica em energia.

Palavras-chave: biodiesel, glicerina bruta, nutrição, alimento alternativo

\section{Crude Glycerin: residue of biodiesel and its use in feed for poultry and pigs}

\section{Abstract}

In today's world, where maize is being used for ethanol production, the use of alternative foods feed assumes a relevant role. The Brazilian poultry and pork have gone through periods of constant instability, especially for the low price 
GOMIDE, A.P.C. et al. Glicerina bruta na alimentação de aves e suínos. PUBVET, Londrina, V. 5, N. 26, Ed. 173, Art. 1167, 2011.

of the product associated with the high costs of production and supply has been the focus of greater participation in the total cost of production, representing a percentage from 70.0 to $75,0 \%$ of the total cost of the activity. Because of this and virtues of the ingredients used in feed for swine and poultry in Brazil are corn and soybean meal, a change in the price of these inputs can have direct impacts on the producer's profit margin. In recent years, research efforts involving the use of alternative foods, especially byproducts or waste resulting from industrial processing of agricultural products and practices of modern mechanization, have aroused the interest of the scientific community. The surveys have been instrumental for the discovery of new ways of using the products and by-product, and limitations for different categories of animals within each species. Currently, besides the agricultural branch of research, studies on the use of renewable energy have been intensified. Among the renewable sources has received great attention biodiesel. However, the increase in biodiesel production could be economically viable only if it finds new uses for the products generated, such as crude glycerin. It has been found that for every $90 \mathrm{~m}^{3}$ of biodiesel produced by transesterification reaction, are generated $10 \mathrm{~m}^{3}$ of crude glycerin. Glycerin when purified can be used in the production of tobacco, in the food industry, beverages and cosmetics products. However, complex processes are needed and high cost of raw material that reaches the purity requirements necessary for these purposes. With the recent surge in biodiesel production and the availability of large quantities of crude glycerin has been interest in its use in animal feed. There are studies whose results indicate the possibility of use of this byproduct in diets as an energy source for pigs and poultry because it is rich in energy.

Keywords: biodiesel, crude glycerin, nutrition, alternative feeds 
GOMIDE, A.P.C. et al. Glicerina bruta na alimentação de aves e suínos. PUBVET, Londrina, V. 5, N. 26, Ed. 173, Art. 1167, 2011.

\section{REVISÃO DE LITERATURA}

\section{1 - BIODIESEL E GLICERINA BRUTA}

A energia é um fator fundamental para o desenvolvimento dos países, tendo-se em vista a dependência no emprego de tecnologias promotoras do desenvolvimento socioeconômico. Cerca de $90 \%$ da energia consumida em todo mundo é proveniente de fonte fóssil, sendo esta não renovável. Assim, vislumbra-se cada vez mais a necessidade em se pesquisar e desenvolver fontes alternativas de energia, como forma de ampliar e diversificar a oferta energética, de maneira ambientalmente sustentável (SOUSA et al., 2006).

A utilização de fontes alternativas de energia é uma das prioridades atuais, que vem contribuir significativamente para contornar os graves problemas ocasionados pelo desenvolvimento tecnológico. A preocupação atual pela redução da poluição e a crise energética têm estimulado o mercado mundial de biocombustíveis. A economia global mantém-se em crescimento e a demanda por energia limpa e recursos renováveis encontra-se em contínuo aumento (BILGEN et al., 2006).

Neste sentido, a busca intensiva por combustíveis alternativos ao petróleo, como o biodiesel, apresenta grande importância principalmente para os países emergentes, uma vez que sua produção auxilia na conservação do meio ambiente, mediante a redução dos gases responsáveis pelo aquecimento global, e contribui para o desenvolvimento social mediante a geração de empregos (OLIVEIRA et al., 2006).

HILL et al. (2006) destacaram que os biocombustíveis para serem viáveis, devem fornecer benefícios ambientais, serem economicamente competitivos e ainda serem produzidos em larga escala, sem comprometer a produção de alimentos.

EXPEDITO (2003) definiu biodiesel como um combustível renovável, biodegradável e ambientalmente correto. Sua constituição é uma mistura de ésteres etílicos ou metílicos de ácidos graxos, obtidos pela transesterificação de quaisquer triglicerídeos com álcool de cadeia curta, metanol ou etanol. O 
GOMIDE, A.P.C. et al. Glicerina bruta na alimentação de aves e suínos. PUBVET, Londrina, V. 5, N. 26, Ed. 173, Art. 1167, 2011.

tipo de óleo para produção do biodiesel pode ser obtido de vegetais, gorduras animais e resíduos domésticos, de restaurante industrial e de rede de "fast food". Na área vegetal, as principais fontes de óleo são: soja, girassol, amendoim, canola, palma (dendê), algodão e mamona. Na área animal, o sebo de boi, a gordura de frango e dos suínos são as principais fontes de óleo para produção do biodiesel.

A mistura de uma fonte de óleo com um álcool (normalmente metanol) e um catalisador (hidróxido de sódio ou potássio) possibilita a ruptura das moléculas de triglicerídios em metil ésteres, chamados de biodiesel, e glicerol (propano-1,2,3-triol). Para cada litro de biodiesel produzido, aproximadamente $80 \mathrm{~g}$ de glicerol são obtidos (KERR et al., 2008).

Em linhas gerais, no processo industrial de produção do biodiesel, é utilizada uma quantidade de álcool em excesso para a ocorrência da reação. Ao final do processo ocorre a separação entre a fase dos ésteres de ácidos graxos, que constitui o biodiesel, e a fase aquosa, que consiste da glicerina bruta, contendo o excesso de álcool não reagido, assim como água e outras impurezas. Parte deste álcool não reagido é recuperado ao final do processo e reutilizado, havendo a sobra de um resíduo de álcool na glicerina bruta (Figura 1). O resultado dessa reação química é a obtenção do biodiesel e tendo como subproduto a glicerina bruta, com teores de glicerol variando de 80 a 95\% (RAMOS et al., 2000)

Nas plantas de produção de biodiesel no Brasil, o álcool utilizado é o metanol, assim como o catalisador mais utilizado é o hidróxido de sódio. Desta forma, existe também um resíduo de sódio na glicerina bruta gerada neste processo. 
GOMIDE, A.P.C. et al. Glicerina bruta na alimentação de aves e suínos. PUBVET, Londrina, V. 5, N. 26, Ed. 173, Art. 1167, 2011.

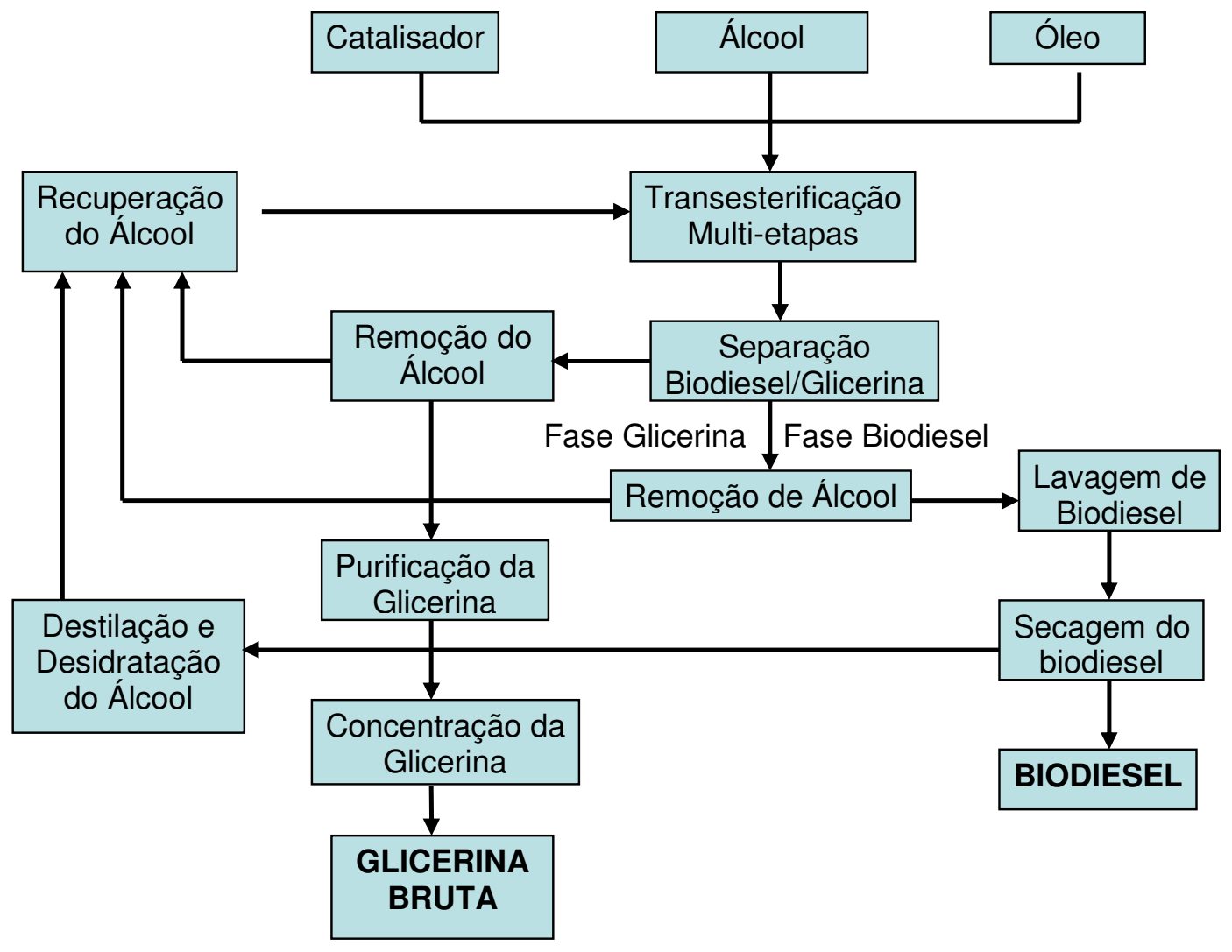

Figura 1: Processo de obtenção do Biodiesel e do Glicerol.

PARENTE, E.J. de S., 2003

No Brasil, a produção e comercialização de biodiesel possuem importantes vantagens devido à grande disponibilidade de matéria-prima para sua produção e ao crescimento contínuo da indústria de óleos vegetais e etanol (OLIVEIRA et al. 2006, OISTI, 2007).

Há de se destacar que o Brasil conta com o Programa Nacional de Produção e Uso do Biodiesel (PNPB), segundo a AGÊNCIA NACIONAL DO PETRÓLEO (2010), desde $1^{\circ}$ de janeiro de 2010, o óleo diesel comercializado em todo o Brasil contém $5 \%$ de biodiesel. Esta regra foi estabelecida pela Resolução no 6/2009 do Conselho Nacional de Política Energética (CNPE), publicada no Diário Oficial da União (DOU) em 26 de outubro de 2009, que aumentou de $4 \%$ para $5 \%$ o percentual obrigatório de mistura de biodiesel ao 
GOMIDE, A.P.C. et al. Glicerina bruta na alimentação de aves e suínos. PUBVET, Londrina, V. 5, N. 26, Ed. 173, Art. 1167, 2011.

óleo diesel (MINISTÉRIO DE MINAS E ENERGIA, 2010). A adição de até $5 \%$ de biodiesel ao diesel de petróleo foi amplamente testada, dentro do Programa de Testes coordenado pelo Ministério de Ciência e Tecnologia, que contou com a participação da Associação Nacional dos Fabricantes de Veículos Automotores (ANFAVEA, 2010). Os resultados demonstraram, até o momento, não haver a necessidade de qualquer ajuste ou alteração nos motores e veículos que utilizem essa mistura.

A lei que regulamenta o biodiesel no Brasil é a lei no. 11.097, de janeiro de 2005 (AGÊNCIA NACIONAL DO PETRÓLEO, 2010), nela estão especificadas todas as regras de produção e comercialização de Biodiesel.

Por outro lado, a produção do biodiesel a partir do óleo extraído de frutos e sementes oleaginosos deverá aumentar a oferta de subprodutos (farelos e tortas), cuja utilização é limitada na alimentação de suínos e de aves. Já a glicerina bruta é aparentemente o único subproduto associado à cadeia produtiva do biodiesel que tem maior valor energético, podendo contribuir favoravelmente em dietas para suínos e aves, neste panorama de aumento do custo alimentar da energia.

A utilização da glicerina bruta na formulação de rações para aves e suínos desperta interesse imediato por se constituir em um produto rico em energia (4.320 kcal de energia bruta por $\mathrm{kg}$ para o glicerol puro) e com alta eficiência de utilização pelos animais. Outro aspecto que justifica a aplicação desse subproduto da indústria do biodiesel na produção de alimentos para animais é que parte das matérias primas renováveis produzidas para atender finalidades energéticas retornarão à cadeia alimentar para gerar produtos de alto valor nutricional (MENTEN et al., 2009).

A diferença de valores de energia bruta do subproduto do biodiesel (glicerina bruta) é uma maneira indireta de estabelecer a eficiência do processo de produção de biodiesel. KERR et al. (2008) mencionaram que a qualidade da glicerina bruta obtida da reação química depende do equipamento empregado. Quanto menor o valor de energia, mais eficiente é a transformação, ficando como produto final somente glicerol e não parte de 
GOMIDE, A.P.C. et al. Glicerina bruta na alimentação de aves e suínos. PUBVET, Londrina, V. 5, N. 26, Ed. 173, Art. 1167, 2011.

glicerol e parte de triglicerídios intactos. Também o nível de sódio da glicerina bruta deve ser avaliado para incluí-lo como nutriente na formulação de dietas para os animais. Sob o ponto de vista da formulação, as variações de energia e de sódio, associadas à variação do metanol, podem restringir a utilização da glicerina bruta como fonte alternativa de energia para a alimentação animal.

Recentemente no Brasil, os estudos de MENTEN et al. (2008) e BERENCHTEIN (2008) demonstraram que a glicerina pode se constituir em um ingrediente energético com potencial para uso em dietas de frangos de corte e suínos em crescimento e terminação, respectivamente.

\section{2- GLICEROL: CARACTERIZAÇÃO E METABOLISMO EM ANIMAIS NÃO RUMINANTES}

O glicerol ou propano-1,2,3-triol (Figura 2) é um composto orgânico pertencente à função álcool, líquido à temperatura ambiente $\left(25^{\circ} \mathrm{C}\right)$, solúvel em água, de aspecto viscoso, sem odor e com sabor adocicado (IUPAC, 1993).

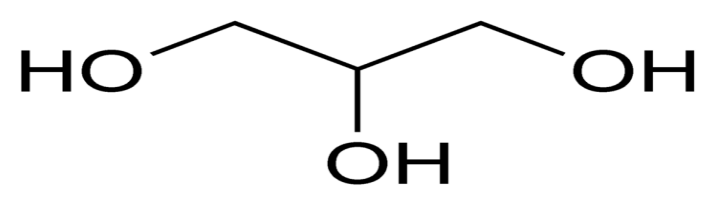

Figura 2: Fórmula estrutural plana do glicerol

É derivado tanto de fontes naturais, das gorduras animais e dos óleos vegetais, quanto da indústria petroquímica. É obtido de triglicerídeos a partir do processo de produção de sabões, do isolamento dos ácidos graxos e, atualmente, pela transesterificação, durante a obtenção do biodiesel.

O glicerol tem mais de 1500 aplicações, desde cosméticos e produtos farmacêuticos até alimentos e outros (PIESKER \& DERSJANT-LI, 2006). Na Comunidade Européia, o glicerol está registrado como aditivo de alimento, sem limite de inclusão (PIESKER \& DERSJANT-LI, 2006). A legislação Norteamericana atribui ao glicerol o status GRAS (geralmente reconhecido como 
GOMIDE, A.P.C. et al. Glicerina bruta na alimentação de aves e suínos. PUBVET, Londrina, V. 5, N. 26, Ed. 173, Art. 1167, 2011.

seguro), quando usado como aditivo alimentar segundo as boas normas de fabricação e alimentação inclusive na alimentação humana (MENTEN et al., 2008).

No entanto, os processos necessários para que a glicerina bruta atinja um grau de pureza necessária para a sua utilização em fins alimentícios e farmacêuticos são complexos e de alto custo (DINIZ, 2005), tendo em vista que a glicerina bruta possui impurezas como água, catalisador (ácido ou alcalino), álcool (não reagido), impurezas provindas dos reagentes, ácidos graxos, ésteres, etanol ou metanol, propanodióis, monoésteres, oligômeros de glicerina e polímeros (PINTO et al., 2008).

Sendo assim, uma alternativa viável e de baixo custo seria a utilização do glicerina bruta na alimentação de suínos (MOUROT et al., 1994; KIJORA et al., 1995; LAMMERS et al., 2007b).

O glicerol é um componente do metabolismo normal dos animais, sendo encontrado na circulação e nas células. Ele é derivado da lipólise no tecido adiposo, da hidrólise dos triglicerídeos das lipoproteínas do sangue e da gordura dietética (LIN, 1977). Entretanto, existem poucas informações sobre as implicações metabólicas da suplementação exógena de glicerol na dieta, especialmente quando a suplementação atinge grandes proporções como um ingrediente energético das rações. De acordo com LIN (1977), o glicerol é bem absorvido no intestino de ratos, porém menos rapidamente do que a glicose.

Além disso, o glicerol também é absorvido no estômago de ratos, porém menos rapidamente do que no intestino.

Segundo BERGMAN (1968), tem-se observado em animais em jejum que as concentrações de ácidos graxos e glicerol são similares na corrente sanguínea associando que ambos têm distribuição similar.

Uma vez absorvido, o glicerol pode ser convertido em glicose, via gliconeogênese, ou oxidado, para a produção de energia, via glicólise e Ciclo de Krebs (ROBERGS E GRIFFIN, 1998). A quantidade de glicose gerada depende do estado metabólico e do nível de glicerol consumido (PLUSKE, 2007). 
GOMIDE, A.P.C. et al. Glicerina bruta na alimentação de aves e suínos. PUBVET, Londrina, V. 5, N. 26, Ed. 173, Art. 1167, 2011.

No fígado e no tecido adiposo, o glicerol é um precursor para a síntese de triacilgliceróis e de fosfolipídios, sendo liberado do catabolismo do triacilglicerol, convertido à glicose via fosforilação do glicerol-3-fosfato e catalisado pela glicerol quinase, e então participa da gliconeogênese ou é oxidado via glicólise e Ciclo de Krebs, promovendo energia prontamente disponível (Figura 3), sendo em média responsável pela produção de 22 mols de ATP por mol de glicerol (MOUROT et al., 1994; BEST, 2006).

O glicerol adicionado às dietas chega ao fígado via veia porta e atua como precursor gliconeogênico da mesma maneira que o glicerol oriundo do catabolismo do triacilglicerol (PLUSKE, 2007).

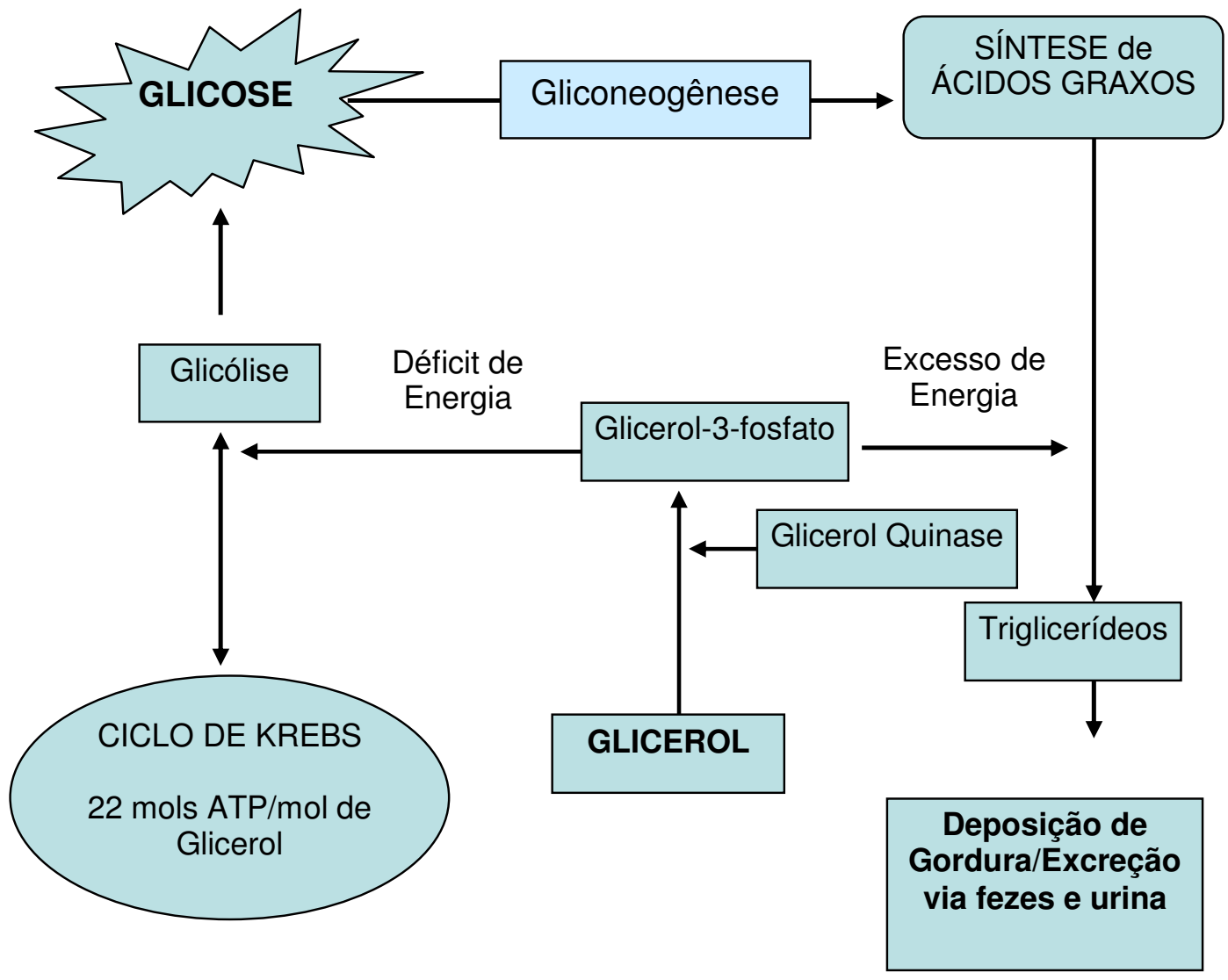

Figura 3: Ilustração do Metabolismo do Glicerol. Adaptado de BEST, 2006 
GOMIDE, A.P.C. et al. Glicerina bruta na alimentação de aves e suínos. PUBVET, Londrina, V. 5, N. 26, Ed. 173, Art. 1167, 2011.

CHAMBERS e DEUEL (1925) demonstraram o potencial gliconeogênico do glicerol. Após fornecerem $8,5 \mathrm{~g}$ de glicerol a dois cachorros por via estomacal, obtiveram recuperação quase total de glicose adicional na urina dos animais. LIN (1977) indicou níveis normais de glicerol plasmático como sendo de 0,1 $\mathrm{mM}$ em ratos e 0,05-0,1 mM em humanos. Em frangos, SIMON et al. (1996) encontraram nível semelhante de $0,65 \mathrm{mM}$ de glicerol plasmático, entretanto a concentração aumentou para 4,36 mM com o fornecimento de $5 \%$ de glicerol na dieta e variou de 11 a $54 \mathrm{mM}$ com a suplementação de $10 \%$ de glicerol na dieta. SIMON et al. (1997) determinaram também que, em frangos recebendo $10 \%$ de glicerol na dieta, a concentração de glicerol no músculo do peito aumentou de $0,4 \mu \mathrm{mol} / \mathrm{g}$ para $7,7 \mu \mathrm{mol} / \mathrm{g}$, enquanto no fígado dessas aves aumentou de $18 \mu \mathrm{mol} / \mathrm{g}$ para $40 \mu \mathrm{mol} / \mathrm{g}$.

O efeito do glicerol dietético na atividade lipogênica foi estudado de forma comparativa em ratos e frangos (LIN et al., 1976). A adição de $20 \%$ de glicerol na dieta de ratos por 3 semanas causou aumento do peso do fígado e um aumento marcante na atividade de enzimas lipogênicas no fígado (sintetase de ácidos graxos, enzima málica e enzima da clivagem do citrato), entretanto sem um aumento concomitante na síntese de ácidos graxos in vivo no fígado. Por outro lado, em frangos alimentados por 3 semanas com dieta contendo $20 \%$ de glicerol, não houve alteração no peso do fígado e ocorreu uma queda na atividade de enzimas lipogênicas no fígado, assim como na taxa de síntese de ácidos graxos. No tecido adiposo de ratos, não houve alteração na atividade das enzimas lipogênicas nem na síntese de ácidos graxos com a dieta rica em glicerol. Ficou evidente que a alimentação de animais não ruminantes com glicerol provoca respostas espécie-específicas e também órgão-específicas.

Além de servir como fonte de energia, o glicerol também pode ter efeitos positivos sobre a retenção de aminoácidos ou nitrogênio, conforme sumarizado por CERRATE et al. (2006); a ação do glicerol inibindo a atividade das enzimas fosfoenolpiruvato carboxiquinase e glutamato desidrogenase pode resultar em economia dos aminoácidos gliconeogênicos e favorecer a deposição de proteína corporal. 
GOMIDE, A.P.C. et al. Glicerina bruta na alimentação de aves e suínos. PUBVET, Londrina, V. 5, N. 26, Ed. 173, Art. 1167, 2011.

\section{3- VALOR ENERGÉTICO DA GLICERINA BRUTA}

O grande interesse na utilização da glicerina bruta na alimentação animal é devido ao seu valor energético. Na realidade, o valor energético da glicerina bruta, resultante de cada processo industrial, deve ser determinado em função de sua pureza em glicerol, resíduos de ácidos graxos e, diversas impurezas que podem estar presentes no produto.

DOZIER et al. (2008), através do método de coleta total de excretas, determinaram os valores de energia metabolizável aparente corrigida para o nitrogênio (EMAn) da glicerina bruta (86,95\% de glicerol, 280 ppm de metanol, 1,26\% de sódio e energia bruta de $3.625 \mathrm{kcal} / \mathrm{kg}$ ) para frangos de corte de diferentes idades. Utilizando dietas não corrigidas para o teor de sódio, em aves de 4 a 11, 17 a 25 e 37 a 45 dias de idade, foram observados, respectivamente, os valores de EMAn de $3.621,3.331$ e $3.349 \mathrm{kcal} / \mathrm{kg}$. Os autores reportaram, pela avaliação conjunta de todas as fase de criação, o valor de EMAn de $3.434 \mathrm{kcal} / \mathrm{kg}$, o que corresponde a 95\% da energia bruta da glicerina. Isto indica que a glicerina bruta é utilizada eficientemente por frangos de corte.

LAMMERS et al. (2008), pelo método do indicador indigestível ( $1 \%$ de celite como cinza insolúvel), determinaram os valores de energia metabolizável corrigida para o nitrogênio (EMAn) da glicerina bruta (86,95\% de glicerol, 280 ppm de metanol, $1,26 \%$ de sódio) para galinhas poedeiras. Analisando os dados por regressão polinomial, foi encontrado o valor de $3.805 \mathrm{kcal} / \mathrm{kg}$ para energia bruta na glicerina bruta para galinhas poedeiras, sendo este semelhante ao valor de energia metabolizável da glicerina utilizada no estudo $(3.625 \mathrm{kcal} / \mathrm{kg})$, novamente demonstrando o alto grau de aproveitamento energético por galinhas poedeiras.

Para suínos na fase de crescimento o valor de energia metabolizável para glicerina bruta é de $3.207 \mathrm{kcal} / \mathrm{kg}$ (LAMMERS et al., 2008a) e para suínos na fase de terminação é de $3.772 \mathrm{kcal} / \mathrm{kg}$ (LAMMERS et al., 2007c).

LAMMERS et al. (2008b), através do método de coleta total de fezes e urina, mediram os valores de energia digestível (ED) e metabolizável (EM) da 
GOMIDE, A.P.C. et al. Glicerina bruta na alimentação de aves e suínos. PUBVET, Londrina, V. 5, N. 26, Ed. 173, Art. 1167, 2011.

glicerina bruta $(86,95 \%$ de glicerol, $280 \mathrm{ppm}$ de metanol, 1,26\% de sódio e energia bruta de $3.625 \mathrm{kcal} / \mathrm{kg}$ ) para leitões na fase de creche (três experimentos) e suínos em terminação (dois experimentos). Para os cinco experimentos, foi calculado que a ED da glicerina bruta correspondeu, em média, a $92 \%$ da energia bruta e que a razão EM:ED foi de $96 \%$. Na avaliação global, a ED da glicerina bruta para suínos foi de $3.344 \mathrm{kcal} / \mathrm{kg}$ e a EM foi de $3.207 \mathrm{kcal} / \mathrm{kg}$. Entretanto, os autores relataram que houve um declínio na estimativa da EM da glicerina com níveis crescentes de inclusão na ração para leitões na fase de creche $(3.601,3.329$ e $2.579 \mathrm{kcal} / \mathrm{kg}$ de glicerina bruta para 5,10 , e $20 \%$ de inclusão, respectivamente); esse declínio não ocorreu para animais em terminação.

É importante ressaltar que ao formular rações para aves e suínos, o valor de energia metabolizável da glicerina bruta será proporcional ao seu nível de glicerol, ou seja, deve ser considerado o teor de glicerol e a energia bruta do glicerol como sendo de $4.320 \mathrm{kcal} / \mathrm{kg}$ conforme sugerido por LAMMERS et al. (2008b).

Ao se comparar os valores da energia metabolizável aparente da glicerina bruta com os valores da energia metabolizável aparente do milho que para aves é de $3.381 \mathrm{kcal} / \mathrm{kg}$ e para suínos é de $3.340 \mathrm{kcal} / \mathrm{kg}$, segundo ROSTAGNO et al. (2005), verifica-se o potencial da utilização da glicerina bruta como ingrediente energético em ração para estes animais.

\section{4- UTILIZAÇÃO DA GLICERINA BRUTA NA ALIMENTAÇÃO DE SUÍNOS E AVES}

A utilização da glicerina bruta na alimentação animal já foi, no passado, alvo de estudo (BERNAL et al., 1978; WAGNER, 1994; SIMON et al., 1997) e, com o recente estímulo à produção de biodiesel, atualmente na literatura, encontramos alguns trabalhos desenvolvidos com o objetivo de determinar o efeito da glicerina bruta, proveniente de diferentes fontes e características, sobre o desempenho, características de carcaça e de qualidade de carne de 
GOMIDE, A.P.C. et al. Glicerina bruta na alimentação de aves e suínos. PUBVET, Londrina, V. 5, N. 26, Ed. 173, Art. 1167, 2011.

suínos e aves, bem como sobre características químicas e valores energéticos do glicerol.

HOLTKAMP et al. (2007) relataram que a glicerina bruta, proveniente da produção de biodiesel, contém aproximadamente $85 \%$ de glicerol, $10 \%$ de água e $3-7 \%$ de sais. Possui energia bruta na faixa de 3.600 a $3.850 \mathrm{kcal} / \mathrm{kg}$, dependendo de sua pureza (glicerol puro contém $4305 \mathrm{kcal} / \mathrm{kg}$ de energia bruta).

Em frangos, SIMON et al. (1996) avaliando 5, 10, 15, 20 e 25\% de inclusão de glicerina bruta na dieta, e concluíram que até $10 \%$ deste subproduto pode promover resultados benéficos no desempenho dos animais. Entretanto, os mesmos autores, em 1997, ao utilizarem $10 \%$ de glicerina bruta em dietas suplementadas com aminoácidos industriais e baixos níveis de proteína bruta, não observaram efeitos da adição da glicerina no desempenho dos animais. WALDROUP (2006) demonstrou que em animais com até 16 dias de idade, a glicerina bruta pode ser usada em até $10 \%$. Entretanto, quando a glicerina for usada em todas as dietas, até o abate, este nível não deverá ultrapassar $5 \%$ pois afeta o consumo da dieta. Já o nível de $10 \%$ na dieta comprometeu a qualidade da carcaça. CERRATE et al. (2006) confirmaram as observações de WALDROUP (2006) quando verificaram que a inclusão de $10 \%$ de glicerina bruta comprometeu o desempenho, afetando negativamente o consumo de ração, o peso final e conseqüentemente a conversão alimentar dos frangos. Quanto às características de carcaça, o mesmo tratamento reduziu o peso (absoluto e relativo da carcaça) do peito, de asas e de coxa. Entretanto, em um segundo experimento, para aves na mesma categoria, os mesmos autores, testando a inclusão de 0, 2,5 e 5\% de glicerina bruta na dieta, não observaram perda de desempenho dos frangos. No entanto, encontraram um aumento na porcentagem de peito das aves.

Avaliando o farelo de soja enriquecido com $10 \%$ de glicerina bruta na dieta de frangos de corte, MENTEN et al. (2008), concluíram que o mesmo pode ser utilizado durante todo o período de criação, sem afetar o desempenho 
GOMIDE, A.P.C. et al. Glicerina bruta na alimentação de aves e suínos. PUBVET, Londrina, V. 5, N. 26, Ed. 173, Art. 1167, 2011.

das aves, desde que sejam feitos os devidos ajustes nutricionais, em termos, de energia, aminoácidos e sódio.

Em poedeiras, LAMMERS et al. (2008), trabalhando com a inclusão de glicerina bruta em até $15 \%$, identificaram que aves com 40 semanas de idade, não tiveram suas características produtivas afetadas (produção de ovo, massa de ovo, consumo de alimento).

Avaliando até $10 \%$ de inclusão de glicerina bruta proveniente da produção do biodiesel, na dieta de leitões na fase de creche, LAMMERS et al. (2007a) não observaram qualquer efeito no desempenho dos animais.

GROESBECK et al. (2008), utilizando inclusão de 3,0; 6,0 e 12,0\% deste subproduto, associados ou não com óleo de soja, em dietas para suínos na fase de creche, observaram um efeito linear positivo no ganho diário de peso dos leitões que receberam glicerina bruta na dieta, sem, no entanto, afetar o consumo diário de ração e a conversão alimentar. A glicerina bruta, devido ao sabor adocicado, pode ter influenciado melhorando a palatabilidade da dieta, atuando positivamente no desempenho destes animais, PIESKER \& DERSJANTLI (2006) também relataram que o sabor adocicado pode contribuir para esta melhoria.

A glicerina bruta, além de ser uma fonte energética, pode ser empregada nas dietas para melhorar a qualidade dos peletes (granulado) das rações. GROESBECK (2002), trabalhando com dietas de suínos, demonstrou que a inclusão de glicerina bruta melhorou a qualidade dos peletes e diminuiu o custo energético da peletização, obtendo os melhores resultados com 3 e $6 \%$ de glicerina bruta adicionada. A glicerina bruta também pode reduzir o pó das dietas e dos suplementos minerais e vitamínicos.

MOUROT et al. (1994), avaliando inclusão de $5 \%$ de glicerina bruta, proveniente de sebo ou óleo vegetal, não relataram efeito no desempenho dos animais, suínos em crescimento e terminação, porém observaram maior capacidade de retenção de água no músculo Longissimus dorsi, resultando em uma carne de melhor qualidade. 
GOMIDE, A.P.C. et al. Glicerina bruta na alimentação de aves e suínos. PUBVET, Londrina, V. 5, N. 26, Ed. 173, Art. 1167, 2011.

KIJORA et al. (1995), avaliando a inclusão de até 30\% de glicerina bruta de fonte vegetal para suínos em crescimento e terminação, observaram menores ganhos diários de peso e piores conversões alimentares, para o maior nível de inclusão, sem, no entanto, afetar as características de carcaça e qualidade de carne destes animais.

KIJORA \& KUPSCH (1996) utilizando glicerina bruta ou purificada, em até $10 \%$ de inclusão em dietas de suínos em crescimento e terminação, observaram que quando comparado ao tratamento controle, na fase de crescimento, $10 \%$ de inclusão de glicerina bruta, proporcionou melhor conversão alimentar. Já nos períodos de terminação e total do experimento não observaram qualquer efeito na adição de glicerina bruta nas características de carcaça e qualidade de carne.

Segundo KIJORA et al. (1997) a inclusão da glicerina proporcionou melhores consumos diários de ração e conseqüentemente melhores ganhos diários de peso, quando comparado a outros ingredientes energéticos (óleos vegetais e ácidos graxos) nas dietas para a mesma categoria de suínos.

BERENCHTEIN (2008) verificou que a glicerina bruta pode ser utilizada como ingrediente energético nas rações de suínos em crescimento e terminação até o nível de $9 \%$, sem afetar sensivelmente o desempenho, as características de carcaça e a qualidade da carne dos animais.

GOMIDE (2010) avaliando a inclusão de glicerina bruta em dietas para suínos machos castrados em terminação em substituição ao milho verificou que esta pode ser utilizada como ingrediente energético até o nível de 16\% sem prejudicar o desempenho, as características de carcaça e melhorando a qualidade de carne.

\section{5- REGISTRO DA GLICERINA BRUTA COMO INGREDIENTE PARA RAÇÃO ANIMAL}

A disponibilidade da glicerina bruta no Brasil aumentou consideravelmente nos últimos anos, com o aumento na produção de biocombustíveis e a incorporação obrigatória de $5 \%$ destes no diesel de petróleo, mas só 
GOMIDE, A.P.C. et al. Glicerina bruta na alimentação de aves e suínos. PUBVET, Londrina, V. 5, N. 26, Ed. 173, Art. 1167, 2011.

recentemente, em setembro de 2010, o Ministério da Agricultura, Pecuária e Abastecimento (MAPA, 2010) aprovou a inclusão do glicerol como ingrediente para ração animal, reconhecendo que o produto apresenta um ótimo potencial nutritivo para a nutrição animal.

As empresas, a partir de agora, têm que registrar o produto no Mapa e garantir a qualidade dentro dos padrões que o ministério estabeleceu que é de, no mínimo, $80 \%$ de glicerol na glicerina bruta, no máximo $12 \%$ de umidade e no máximo 150 ppm de metanol, sendo que os níveis de sódio e cloro no produto ficam em aberto, devendo ser informado pelo fabricante.

\section{REFERÊNCIAS BIBLIOGRÁFICAS}

SOUSA, G. S.; PIRES, M. M.; ALVES, J. M. Análise da potencialidade da produção de biodiesel a partir de óleos vegetais e gorduras residuais. In: SEMINÁRIO DE INICIAÇÃO CIENTÍFICA DA UESC, 11, 2006, Santa Cruz. Anais... Santa Cruz: UESC, 2006. p. 477-478.

BILGEN, S.; KELES, S.; KAYGUSUZ, A.; SARI, A.; KAYGUSUZ, K.; Renew. Sust. Energ.Rev.DOI:10.1016/j.rser.2006.07.016

OLIVEIRA, L. B.; MUYLAERT , M. S., ; ROSA, L. P.; BARATA, M.; ROVERE, E. Renew. Sust. Energ.Rev. DOI:10.1016/j.rser.2006.10.013

HILL, J.; TILMAN, D.; POLASKY, S.; TIFFANY, D. Environmental, economic, and energetic costs and benefits of biodiesel and etanol biofuels. Proceedings of the National Academy of Sciences of the United States of America. Vol: 103, Issue:30, pages 11206 - 11210. July, 2006.

EXPEDITO, J. de S. Biodiesel: Uma aventura tecnológica num país engraçado. Rede Baiana de Biocombustíveis, Salvador -BA, 2003.

KERR, B. J.; HONEYMAN, M.; LAMMERS, P. Feeding Bioenergy Coproducts to Swine. Iowa Pork Industry Center, 2008.

RAMOS, L. P. (2000). Aproveitamento integral de resíduos agrícolas e agro-industriais.

Disponível em: http//www.asfagro.org.br/trabalhos_tecnicos/biodiesel/combustível. Acesso em 13 de junho de 2010.

PARENTE, E. J. de S. 2003. Biodiesel - Uma aventura tecnológica num país engraçado. Editora Unigráfica: Fortaleza-CE.

OISTI Ò OFFICE OF SCIENTIFIC \& TECHNICAL INFORMATION - 2007 http://www.osti.gov/bridge/servlets/purl/837189-Yhbgdr/native/837189.pdF. Acessada em abril de 2010. 
AGÊNCIA NACIONAL DO PETRÓLEO. Disponível em: http://www.anp.gov.br. Acesso em 18 de junho de 2010.

MINISTÉRIO DE MINAS E ENERGIA. Disponível em: www.mme.gov.br. Acesso em 15 de junho de 2010.

ASSOCIAÇÃO NACIONAL DOS FABRICANTES DE VEÍCULOS AUTOMOTORES - BRASIL (ANFAVEA). Disponível em: http://www.anfavea.com.br/noticias/biodiesel.html. Acesso em 18 de junho de 2010.

MENTEN, J. F. M.; MIYADA, V. S.; BERENCHTEIN, B. Glicerol na alimentação animal. Disponível em http://www.agrolink.com.br/downloads/glicerol 2009-03-13.pdf. Acesso em 15 de agosto de 2010.

MENTEN, J. F. M.; PEREIRA, P. W. Z.; RACANICCI, A. M. C. Avaliação da glicerina proveniente do biodiesel como ingrediente para rações de frango de corte. In: CONFERENCIA APINCO 2008 DE CIENCIA E TECNOLOGIA AVÍCULAS, 2008, Santos. Anais. Campinas: Fundação APINCO de Ciência e Tecnologia Avícolas, 2008. p. 66.

\section{BERENCHTEIN, B. Utilização de glicerol na dieta de suínos em crescimento e}

terminação. 2008. 45 p. Dissertação (Mestrado em Agronomia, Programa Ciência Animal e Pastagens) - Escola Superior de Agricultura "Luiz de Queiroz", Universidade de São Paulo, Piracicaba, 2008.

INTERNATIONAL UNION OF PURE AND APPLIED CHEMISTRY (IUPAC) 1993. Disponível em: http://www.iupac.org. Acesso em 20 de junho de 2010.

PIESKER, M. e Y. DERJANT-LI. 2006. Glycerol in Animal Nutrition - Versatile co-product of biodiesel production. Feedmagazine Kraftfutter.

DINIZ, G. De coadjuvante a protagonista: glicerina bruta obtida na produção de biodiesel pode ter muitas aplicações. Ciência Hoje On-line, Rio de Janeiro, 2005. Disponível em:

http://cienciahoje.uol.com.br?controlpanel/materia/view/3973. Acesso em 22 de novembro de 2009.

Pinto, A. C.; GUARIEIRO, L. L. N.; REZENDE, M. J. C.; RIBEIRO, N. M; TORRES, E. A.; LOPES, W. A.; PEREIRA, P. A.; ANDRADE, J. B. de. Produção brasileira de biodiesel. Journal of the Brasilian Chemical Society, Campinas, v.16, p. 1313, 2008.

MOUROT, J.; AUMAITRE, A.; MOUNIER, A.; PEINIAU, P.; FRANÇOIS, A. C. Nutritional and physiological effects of dietary glycerol in the growing pig. Consequences on fatty tissues and post mortem muscular parameters. Livestock Production Science, Amsterdam, v. 38, p. 237-244, 1994.

KIJORA, C.; BERGNER, H.; KUPSCH, R. D.; HAGEMANN, L. Glycerol as a feed component in fattening pigs. Archives of Animal Nutrition, Berlin, v.47, n. 4,p. 345-360, 1995.

LAMMERS, P.; HONEYMAN, M.; KERR, B.J.; WEBER, T.E.; BREGENDAHL, K. Growth performance and carcass characteristics of growing pigs fed crude glycerol. In: 2007 JOINT ANNUAL MEETING OF AMERICAN SOCIETY OF ANIMAL SCIENCE, 2007, San Antonio.

Proceedings... Stanford: Highwire Press Standford University, 2007b. p. 508. 
LIN, E. C. C. Glycerol utilization and its regulation in mammals. Annual Review of Biochemistry, Palo Alto, v.46, p. 465-495, 1977.

BERGMAN, E. N.; STARR, D. J. e REULEIN, S. Glycerol metabolism and gluconeogenesis in the normal and hypoglycemic ketonic sheep. American Journal Physiology, v. 215. 1968. p. 874-880.

ROBERGS, R. A. e GRIFFIN, S. E. 1998. Glycerol: biochemestry, pharmakokinetics and clinical and practical applications. Sprts. Med. 26:145-167.

PLUSKE, J. Evaluation of glycerine as co-product of biodiesel production for the pig industry . Subiaco: Pork Co-operative Research Center, 2007. 200p. (Supplement).

BEST, P. Increased biofuel production will grow supplies og by-products: Glycerine gives na energy option. Feed International, Los Gatos, v.55, n.12, p.20-21, dec. 2006.

CHAMBERS, W. H. \& DEUEL, H. J. Journal of Biological Chemistry. v. 65, p. 21-29, 1925.

SIMON, A.; BERGNER, H.; SCHWABE, M. Glycerol as a feed ingredient for broiler chickens. Archives of Animal Nutrition, Berlin, v. 49, n. 2, p. 103-112, 1996.

SIMON, A.; SCHWABE, M; BERGNER, H. Glycerol supplementation in broiler rations with low crude protein content. Archives of Animal Nutrition, Berlin, v. 50, n. 3, p. 271-282, 1997.

LIN, M. H.; ROMSOS, D. R.; LEVEILLE, G. A. Effect of glycerol on lipogenic enzyme activities and on fatty acid synthesis in the rat and chicken. Journal of Nutrition, v. 106, p. 1668$1677,1976$.

CERRATE, S.; YAN, F.; WANG, Z.; COTO, C.; SACAKLI, P.; WALDROUP, P. W. Evalution of glicerine from biodiesel production as a feed ingredient for broilers. International Journal of Poultry Science, Faisalabad, v.5, n.11, p. 1001-1007, 2006.

DOZIER, W. A. et al. 2008. Apparent Metabolizable Energy of Glycerin for Broiler Chickens. Poult.Sci. 2008. 87:317-322.

LAMMERS, P. J. et al. 2008. Nitrogen-corrected apparent metabolizable energy value of crude glycerol for laying hens. Poult.Sci. 2008 87:104-107.

LAMMERS, P.; KERR, B. J.; WEBER, T. E.; DOZIER, W. A.; KIDD, M. T.; BREGENDAHL, K; HONEYMAN, M. Diestible and metabolizable energy of crud glycerol for growing pigs. Journal of Animal Science, Champaign, v. 86, p. 602-608, 2008a.

LAMMERS, P.; HONEYMAN, M.; BREGENDAHL, K.; KERR, B. J; WEBER, T.; DOZIER, W. A.; KIDD, M. T. Energy value of crude glycerol fed to pigs. Ames: Iowa State University Animal Industry Report, 2007c. (Supplement).

LAMMERS, P.; KERR, B. J.; HONEYMAN, M.; STALDER, K.; DOZIER, W. A.; WEBER. T. E.; KIDD, M. T.; BREGENDAHL, K. Nitrogen-corrected apparent metabolizale energy value of crude glycerol for laying hens. Journal of Animal Science, Champaign, v. 87, n. 1, p .104-107, 2008b. 
ROSTAGNO, H. S. et al. Tabelas Brasileiras para Aves e Suínos; Composição de Alimentos e Exigências Nutricionais. 2a Edição, Viçosa: UFV, Imprensa Universitária, 186 p. 2005.

BERNAL, J. Efecto de la inclusión de glycerol o aceite vegetal a dietas com melaza para suínos e aves em crecimiento. Vet. Mex. v. 3, p. 9194, 1978.

WAGNER, H. Glycerol in animal feeding - a byproduct of alternative fuel production. Muhle Mischfuttertechnik, v. 131, p. 621-622, 1994.

HOLTKAMP, D.; ROTTO, H.; GARCIA, R. Economic cost of major health challenges in large us swine production systems - Part 2. Swine News, North Carolina State University, v. 30, n. 4, May 2007.

WALDROUP, P. 2006. Glycerine, a byproduct of biodiesel production, can be used as a dietary supplement for growing broiler chickens. University of Arkansas. Arkansas Agricultural Experiment Station.

LAMMERS, P.; HONEYMAN, M.; KERR, B. J.; WEBER, T. E. Growth and performance of nursery pigs fed crude glycerol. Ames: Iowa State University Animal Industry Report, 2007a.

(Supplement).

GROESBECK, C. N.; MCKINNEY, L. J.; DEROUCHEY, J. M.; TOKACH, M. D.; GOODBAND, R. D.; DRITZ, S. S.; NELSSEN, J. L.; DUTTLINGER, A. W.; FAHRENHOLZ, A. C.; BEHNKE, K. C. Effect of crude glycerol on pellet mill production and nursery pig growth performance. Journal of Animal Science, Champaing, v. 85, suppl. 1, p. 201-202, 2008.

GROESBECK, C. N. 2002. The Effect of Feed Ingredients on Feed Manufacturing and Growth Performance of Pigs. krex.ksu.edu/dspace/bitstream/2097/523/1

/CrystalGroesbeck2007.pdf.pdf

KIJORA, C. \& KUPSCH, R. D. Evaluation of technical glycerols from "Biodiesel" production as a feed component in fattening of pigs. Lipid-Fett, Weinheim, v. 98, p 240-245, 1996.

KIJORA, C.; KUPSCH, R. D.; BERGNER, H.; WENK, C.; PRABUCKI, A. L. Comparative investigation on the utilization of glycerol, free fatty acids in combination with glycerol and vegetable oil in fattening of pigs. Journal of Animal Physiology and Animal Nutrition, Foulum, v. 77, n.3, p. 127-138, 1997.

GOMIDE, A.P.C. Substituição do milho por glicerina bruta em dietas para suínos em terminação. 2010. 46 p. Mestrado em Zootecnia, Nutrição e Produção de Monogástricos. Universidade Federal de Viçosa, Viçosa, 2010.

MINISTÉRIO DA AGRICULTURA E DO ABASTECIMENTO. SECRETARIA DE DEFESA AGROPECUÁRIA (MAPA). Disponível em: http://www.agricultura.gov.br/. Acesso em 28 de outubro de 2010. 